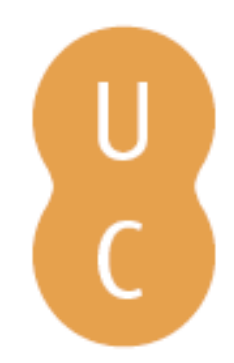

\title{
nombalina
}

\section{Os cavaleiros de Aristófanes: um padrão de caricatura biográfica do político}

Autor(es): $\quad$ Silva, Maria de Fátima

Publicado por: Imprensa da Universidade de Coimbra

URL

persistente:

URI:http://hdl.handle.net/10316.2/32561

DOI:

DOI:http://dx.doi.org/10.14195/978-989-26-0442-8_2

Accessed : $\quad$ 26-Apr-2023 10:20:52

A navegação consulta e descarregamento dos títulos inseridos nas Bibliotecas Digitais UC Digitalis, UC Pombalina e UC Impactum, pressupõem a aceitação plena e sem reservas dos Termos e Condições de Uso destas Bibliotecas Digitais, disponíveis em https://digitalis.uc.pt/pt-pt/termos.

Conforme exposto nos referidos Termos e Condições de Uso, o descarregamento de títulos de acesso restrito requer uma licença válida de autorização devendo o utilizador aceder ao(s) documento(s) a partir de um endereço de IP da instituição detentora da supramencionada licença.

Ao utilizador é apenas permitido o descarregamento para uso pessoal, pelo que o emprego do(s) título(s) descarregado(s) para outro fim, designadamente comercial, carece de autorização do respetivo autor ou editor da obra.

Na medida em que todas as obras da UC Digitalis se encontram protegidas pelo Código do Direito de Autor e Direitos Conexos e demais legislação aplicável, toda a cópia, parcial ou total, deste documento, nos casos em que é legalmente admitida, deverá conter ou fazer-se acompanhar por este aviso. 
Aurelio Pérez Jiménez, Joșé Ribeiro Ferreira

e Maria do Céu Fialho

(COORdinadores)

\section{Adminiftri Principum.}

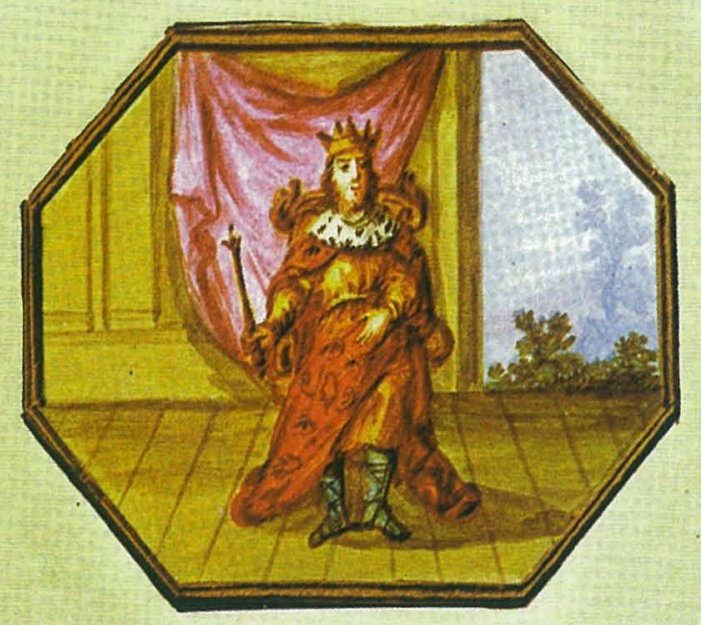

\section{EMBLEM A LIV.}

En tibi plura gerit, quàm lumina prabuit Argos Rex; Aures totidem, quin totidemó, manus. Hec opus Imperio, fidis fupplenda Minijtris, Regi bi funt aures: lumina clara, manus.

\section{- Retrato e a Biografia como estratégia de teorização política}

IMPRENSA DA UNIVERSIDADE DE COIMBRA

Universidad de MálaGa 
(Página deixada propositadamente em branco) 
Aurelio Pérez Jiménez

José RIBEIRo FERREIRA

Maria do Céu Fialho

O RETRATO LITERARIO E A BIOGRAFIA COMO ESTRATÉGIA

\section{DE}

TEORIZACCÃO POLITICA

IMPRENSA DA UNIVERSIDADE DE COIMBRA

UnIVERSIDAD DE MÁlaGa

2004 
Obra publicada com a colaboração de:

Centro de Estudos Clássicos e Humanísticos (Universidade de Coimbra)

International Plutarch Society

Primera edição, Junho de 2004

(c) IMPRENSA DA UnIVERSIDADE DE COIMBRA

(c) Área de Filología Griega. Universidad de Málaga

Coordenação editorial:

Imprensa da Universidade de Coimbra

Área de Filología Griega de la UMA

ISBN: 972-8704-25-9 (PORTUGAL)

ISBN: 84-608-0166-7 (ESPANHA)

Depósito Legal: MA-1420

Impresso em Espanha

Execução gráfica:

IMAGRAF IMPRESORES, S.A.

c/ Nabucco 14

29006 Málaga

Tfno. 952328597

Página de rosto:

"Dos Princepes Transùmptos verdadeiros": Francisco António Novaes Campos, Principe perfeito. Emblemas de D. Joâo de Solórzano. Edição fac-similada do manuscrito da Biblioteca Nacional do Rio de Janeiro oferecido ao Príncipe D. João em 1790 (Prefácio, introdução, comentário e índices por Maria Helena de Teves Costa Ureña Prieto), Instituto de Cultura e Língua Portuguesa, Lisboa, 1985, Emblema LIV, p. 114. 


\section{Os Cavaleiros de Aristófanes UM PADRÃO DE CARICATURA BIOGRÁFICA DO POLÍTICO}

Maria de Fátima Silva

Universidade de Coimbra

É consensual entre os estudiosos de biografia que, embora como género literário autónomo ela seja uma criação da época helenística, não surge nessa fase da literatura grega como um produto inédito ${ }^{1}$. Os ascendentes que para ela se podem encontrar são múltiplos e remontam a padrões muito antigos em que a literatura da Hélade se foi exprimindo ao longo dos tempos. A época clássica deu, à definição do esquema biográfico, um contributo particularmente profícuo, como berço da historiografia, antes de mais, com quem a futura biografia haveria de ter muito em comum, ou pela expressão de uma filosofia política ou ética, onde a busca de um modelo ideal para a comunidade humana e o seu chefe se tornou consequência inevitável da falência da polis democrática. Mas, dentro do que foram as glórias da produção literária da época clássica, o teatro iria trazer também à biografia um manancial de sugestões infindável. Cingindo-me em particular à comédia de sátira política, de que $O s$ Cavaleiros são, entre o corpus conservado, o exemplo mais expressivo, o parentesco de propósitos é, nas suas linhas gerais, evidente; a comédia política, em sentido estrito, visa delinear o retrato de um indivíduo concreto, um herói da vida contemporânea, escolhido de entre os mais populares ou poderosos, com um desenho nítido dos traços que lhe são característicos e que fazem dele um exemplar paradigmático da classe a que pertence. É inegável, por trás do exagero da caricatura, um intuito de verosimilhança, que não desmerece do propósito de ver-

1 Sobre os antecedentes do género, vide A. J. Podlecki, Plutarch. Life of Pericles (Bristol 1987) 6-16; D. A. Russell, 'On reading Plutarch's Lives', G\&R 13 (1966) 139-154.

A. Pérez Jiménez, J. Ribeiro Ferreira, Maria do Céu Fialho (edd), O retrato literário e a biografia como estratégia de teorização política, Coimbra-Málaga, 2004, pp. 23-36. 
dade que é declaradamente o da biografia ${ }^{2}$. Nem ao quadro falta a intenção didáctica, que se tornou parte da natureza do relato biográfico, como género que busca modelos paradigmáticos, sobre cujas virtudes de excelência as novas gerações podem encontrar ideais de comportamento a seguir ${ }^{3}$. Missão idêntica esteve sempre nos propósitos da comédia, passar ao público uma mensagem construtiva e socialmente válida. Apenas a comédia procurou na deformação o seu método próprio. Não falta à caricatura do político superioridade e excelência nas 'virtudes' negregadas que lhe constituem o perfil, não como modelo a reproduzir mas a evitar. É nesta opção por mostrar o que é mau, que lhe foi reconhecida como natural por um teórico do teatro como Aristóteles (Poética 1449a 31-33), que a comédia fixou a sua maneira de traçar a biografia dos demagogos contemporâneos.

Atentemos agora noutros métodos e conteúdos que os autores de biografia enunciaram como próprios do género, e que muito claramente encontramos também nos alicerces de Cavaleiros. Se tomarmos Plutarco como modelo central de biógrafo, na sua qualidade de autor das Vidas Paralelas e de único representante, para nós, deste modelo literário na produção helénica, logo percebemos que faz parte da sua pretensão de retratista não apenas o desenho de personalidades avulsas, mas o permanente cotejo de figuras - quer dentro de cada vida, quer no confronto de modelos - , escolhidas aos pares, de forma a que o produto literário conseguido tenha a força de um padrão universal, de onde saia provado que, independentemente do contexto histórico-social ou da individualidade do retratado, há traços em comum, que constituem a personalidade humana de uma classe de sujeitos. Esta estratégia conduz à ideia de universalidade, que se obtém a partir do confronto de casos concretos. Parece evidente que, mesmo sem ter deste princípio a mesma noção teórica, Aristófanes o pratica, na peça de 424, em plenitude. O retrato que aí produz do político contemporâneo assenta num paralelo, que se deseja conflituoso ou agonístico, de acordo com a natureza da comédia. Mas os dois retratados, em concorrência aberta um com o outro mais do que em paralelo, são ilustres membros do mesmo grupo, semelhantes nas características, ainda que os sucessivos agônes venham a provar o refinamento ou vantagem, e a consequente vitória cómica, de um sobre o outro. Um pormenor de recolha de fontes

Cf., e. g., Plutarco, Vida de Címon 2. 3.

3 Este sentido moralizador pode levar até a alguma distorção, numa perspectiva de idealização positiva dos factos. Plutarco (Vida de Címon 2. 4-5) não deixa de reconhecer que o biógrafo deve evitar pôr em evidência os erros ou falhas do modelo que escolheu. Deve mesmo ser discreto no reconhecimento de que a imperfeição da natureza humana dificilmente produz exemplos de uma arete pura e plena. 
inspiradoras distingue os dois tipos de criação; enquanto a biografia helenística vai sobretudo buscar os seus modelos no passado e na tradição, tornados paradigma por força do ascendente que o tempo produz, a vitalidade da comédia exige que os exemplares que usa sejam colhidos a quente, na contemporaneidade mais imediata.

Na pele do Paflagónio, Cléon, o mais popular dos políticos do momento, é, por natureza, o modelo em uso da classe. Sujeita-o o poeta a um concurso com um adversário, o Salsicheiro, que com ele partilha variados aspectos de personalidade, mas a um nível que transcende o meramente concreto e real, para se situar no plano de uma abstracção universal. O retrato não depende só de um conjunto de elementos de carácter ou de comportamento individuais. Da leitura modelar que proporciona infere-se uma noção mais ampla de vícios e virtudes, que corrige o particular pela ascensão ao genérico ou universal. O paralelo entre ambos desequilibra-se apenas na graduação, que não nas prendas sucessivamente avaliadas. Como alegoria principal da peça, a parceria política / culinária faz jus à supremacia natural de um Salsicheiro na governação. Por isso se torna oportuno o conselho (vv. 214-219): 'Continua a fazer aquilo que já fazes: misturas os negócios públicos, amassa-los todos juntos, numa pasta. O povo, conquista-lo quando quiseres, com umas palavrinhas delicodoces lá da tua especialidade. Tudo o mais necessário à demagogia tem-lo tu de sobra, voz de safado, baixa condição e ar de valdevinos. Tens tudo o que é preciso para a governação'. Do enunciado geral de virtudes sobressai o toque do excesso ou do exagero, que a comédia não dispensa como fonte do necessário burlesco. Ao mesmo tempo que antecipa, para um dos contendores, uma supremacia que o seu ajuste pleno às circunstâncias lhe concede.

$\mathrm{O}$ aspecto que define a biografia como um género à parte face à sua concorrente historiográfica é a focagem, que se traduz na concentração sobre a figura do agente histórico mais do que sobre os factos e a respectiva interpretação. O retrato que daí resulta é uma súmula de linhas de carácter ou de costumes, que delineiam uma personalidade, depois posta à prova dentro da contingência do fluir histórico em que existe. A actuação que, em cada momento concreto, virá a ser a sua funciona como ilustração ou aplicação prática dos traços que a identificam. Delinear personagens foi sempre também atributo da cena, e naturalmente que na determinação do carácter e dos feitos, a biografia é um género eminentemente narrativo, enquanto o teatro é drama, com uma técnica própria de se exprimir pela actuação directa da personagem. É também conforme à biografia o modelo de político que se traça em Cavaleiros, no sentido de que, mais do que factos, são os seus agentes que sobretudo interessam ao narrador. Se está subjacente à peça de 424 um conjunto de episódios próximos que trouxeram Cléon ao primeiro plano da ribalta política - entre os quais o caso de Pilos é prepon- 
derante -, é sobretudo para o seu herói que as atenções confluem e para os traços de personalidade que o justificam como responsável pela proeza.

Mas, através de um ou de outro processo, os dois géneros alcançam o mesmo objectivo: o de focar a atenção sobre um modelo humano, que, antes de mais, determinam nas suas linhas fundamentais. A propósito do mesmo Plutarco, A. Pérez Jiménez ${ }^{4}$ sintetiza, em palavras oportunas, o esquema a produzir: 'Plutarco parece seguir, em primeiro lugar, um esquema que combina os tópicos retóricos fixados desde Isócrates e Xenofonte para a teoria do encómio biográfico, estabelecendo as étapas cronológicas que marcam a evolução ético-política da personagem biografada. De acordo com este esquema, as referências ao genos dos pais, nascimento, caracterização física e espiritual, formação e imitação, vocação pública, primeiros feitos (que exemplificam essa vocação e conferem à personagem a popularidade que possibilita o seu papel histórico como rei, legislador, militar ou político), a acme, a velhice, morte, exéquias e significado póstumo do biografado, podem entrar no relato, por direito próprio'. Esta chave de leitura que Pérez Jiménez destina a Plutarco pode usar-se, com ligeiros ajustes de pormenor, para a análise da caricatura do demagogo em Cavaleiros. O mesmo é dizer que o esquema que Isócrates e Xenofonte estabeleceram, sob forma de um processo técnico, como trama própria do género biográfico, apenas consagrava práticas já antes tacitamente usadas no teatro. De acordo com a mesma síntese, a estrutura do relato biográfico estabelecese como uma linha contínua que, a partir de um ponto inicial, o proémio ou prólogo, desenha o trajecto de uma existência através de uma curva geral, que prossegue da origem, num caminho ascendente até à acme, para desfechar na decadência ou derrocada, que se consuma naturalmente em morte. Ponderam, na determinação deste percurso, os vícios e as virtudes que são fulcrais na concretização de uma vida e na forma como reage ao processo exterior, que a condiciona e dentro do qual se impõe como modelar ou superior.

Cabe ao proémio um conjunto de considerações preliminares, que justificam a preferência por determinada personagem graças ao elenco dos seus traços principais, que a enquadram dentro de um certo tipo humano e social. Na estrutura cómica, o prólogo constitui a réplica natural desta componente, com um âmbito semelhante de funções. Abordemos, sob esta perspectiva, o prólogo de Cavaleiros. O primeiro testemunho sobre Cléon, um dos retratados, é transmitido

4 'La asociación de ideas como criterio formal en las Vidas Paralelas', in J. A. F. Delgado, F. P. Pardo, Estudos sobre Plutarco: aspectos formales. Actas del Simposio Español sobre Plutarco (Madrid 1996) 257. 
por dois escravos que o conhecem bem e, por isso, detêm para o efeito competência qualificada. Os ais e lamentos em que desde logo se multiplicam valorizam a potência da personagem; bem como as maldições que lhe não poupam a deixam no papel de um modelo a evitar (vv. 1-3): 'Ai, ai! Ai, ai! Raio de vida esta! Ai, ai! Ai, ai! Diabos levem esse tal Paflagónio, maldita compra de última hora! Que os deuses estoirem com ele mais os seus intentos!' E logo extravasando do caso particular para os limites de toda uma classe (vv. 6-7): 'Um raio parta os Paflagónios a começar por esse fulano!' Dado o tom do repúdio de uma forma emotiva, a comédia prossegue, através de um monólogo, com o desenho dos grandes traços da personagem, a desenvolver na plenitude do retrato; origem, nome, profissão, linhas principais de personalidade são, em síntese, rapidamente enunciadas (vv. 44-45): 'Um escravo, um Paflagónio, curtidor de profissão, a fajardice em pessoa, a linguinha mais afiada que já se viu'. Vêm depois a bajulice e a mentira, o roubo, a violência contra qualquer rival, a falta de escrúpulo (vv. 46-70). É, portanto, ainda na ausência física do herói que a expectativa é criada e o padrão definido. Estratégia diferente é usada para o esboço do seu concorrente ou paralelo, o Salsicheiro; porque o não conhecem ainda, os dois escravos inspiram-se nas determinações de um oráculo, que os informa sobre a vinda próxima desse salvador; e valem-se da aparição milagrosa do próprio para o desenho das características correspondentes deste segundo herói.

Atentemos nos traços convencionais que definem o ponto de partida para a ascensão de cada concorrente. Importam, para começar, os elementos que se relacionam com o factor origem: região de proveniência, nome, condição social, paternidade. Logo se torna patente que o sucesso do político cómico veste bem numa personagem que é o antídoto do herói da biografia. Nada há que lhe ilustre a origem: o Paflagónio é escravo, importado, recém-adquirido a peso de dinheiro, sem nome de família, um estrangeiro com a mais rasteira das proveniências (vv. 43-44).

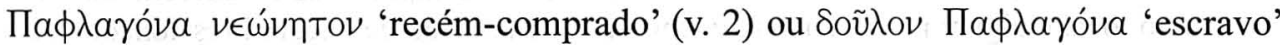
(v. 44) são os dados completos da sua ficha de identidade. A profissão de curtidor (v. 44) completa o quadro, onde a condição social humilde se perfila como a única compatível com a personalidade banal e modesta que se vai desenhando. Não vai muito além deste padrão a base em que assenta o concorrente; profissão, salsicheiro, e quanto a família pode com orgulho afirmar (vv. 185-186; cf. v. 337): 'Filho de patifes, mais nada!' Não fosse a predestinação a fadar um para o fracasso, o outro para o sucesso e nada, na origem, os distinguiria. Ambos são, harmoniosamente, modelos de uma nova vaga de chefes políticos, oriundos dos círculos burgueses da indústria e do comércio, bem distantes das famílias de proprietários abastados com 
pergaminhos aristocráticos, senhoras de uma longa tradição de serviços prestados à pátria, onde a biografia geralmente vai buscar os seus preferidos.

Segue-se-lhe a parafernália de qualidades que a futura actuação se encarregará de exemplificar. As que melhor definem a sua arete são, em grau superlativo, a

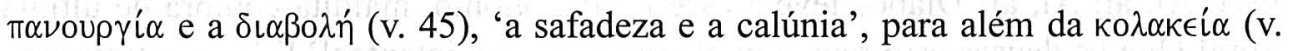
48) e da arte de roubar ( $\dot{\alpha} \rho \pi \alpha ́ \zeta \epsilon \iota \nu, v v .52,56,137)$, em que é exímio. Num espaço que é ainda meramente narrativo, o monólogo próximo do início do prólogo, cabe mesmo um breve discurso directo, onde 'as falinhas mansas' do bajulador ecoam à distância, como modelo de uma estratégia diária na sedução da basbaquice do povo (vv. 50-52). Não menos convencional dentro das regras da narrativa biográfica é o recurso à anedota para ilustrar um mérito concreto. Esse processo também o não despreza Aristófanes, dando ao escravo no papel do general Demóstenes a versão do caso paradigmático de Pilos ${ }^{5}$, onde a roubalheira e a concorrência desleal contra os rivais teve uma ocasião lapidar (vv. 54-57): 'Ainda um dia destes, tinha eu estado, em Pilos, a amassar um pão da Lacónia, e o tipo passa de corrida, deita-lhe a unha e vai ele servir o pão que eu tinha amassado'. Como retoque final no esboço da figura é fun-

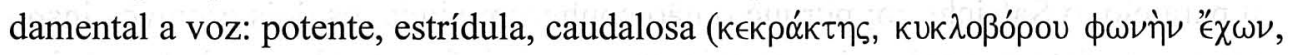

Em 425, corria o sexto ano da guerra do Peloponeso, o general ateniense Demóstenes, ao comando de uma armada, havia tomado de assalto o porto de Pilos, situado na Messénia e vizinho de Esparta. Além da importância desta posição bélica para futuras investidas em território inimigo, a vitória quebrava a tradicional supremacia espartana em campanhas terrestres e tinha, por isso, um grande efeito psicológico. Alertados para o perigo que constituía a presença dos Atenienses em Pilos, os Lacedemónios reorganizaram-se e ocuparam a ilha de Esfactéria, fronteiriça à posição inimiga. As arremetidas de parte a parte eternizavam-se, sem que o empenho diplomático encontrasse para o conflito uma solução satisfatória. Sobretudo porque Cléon, em Atenas, convenceu o povo a colocar condições demasiado pesadas a qualquer negociação de armistício. O prolongamento da situação criou entretanto dúvidas sobre a real capacidade do exército em missão no local e algum mal-estar relativamente à intervenção de Cléon. Pressionado pelas circunstâncias, o demagogo denuncia, na assembleia, a incapacidade dos generais em comando, sobretudo Nícias, seu inimigo pessoal e político, e propõe-se solucionar o caso no prazo limite de vinte dias, se lhe for confiado o comando do exército. Nícias aceita o desafio e pede a demissão; na impossibilidade de recuar, Cléon não hesita. Em Pilos, junta-se a Demóstenes, que entretanto havia planeado uma estratégia de ataque à ilha (cf. Tucídides 4. 27-30), imediatamente posta em execução. $\mathrm{O}$ bom sucesso desta empresa traz a Atenas, como prisioneira, a guarnição espartana de Esfactéria, e um Cléon vitorioso, embora graças a um plano estratégico da inteira responsabilidade de Demóstenes - um pormenor que a comédia não se cansa de valorizar. A cidade recebeu o demagogo com foros de herói nacional, o que naturalmente lhe reforçou o poder político e lhe cativou o apoio incondicional das massas populares. 
v. 137). De resto, o próprio nome do Paflagónio, com insistência repetido neste momento de apresentação, П $\phi \lambda \alpha \gamma \omega \dot{v}$, é portador de uma indesmentível onomatopeia, sugestiva de uma espécie de rebentar de bolha que, em cadeia sonora, recria uma oratória oca e ruidosa ${ }^{6}$. Continuando na síntese geral do modelo, acrescenta-se o dom da vigilância, precioso na luta que um espécime deste calibre tem de travar com rivais ou vítimas (vv. 74-75): 'nada lhe passa despercebido, de olho

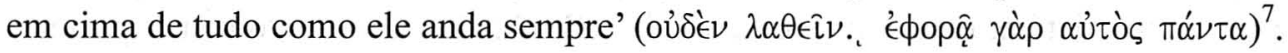

É pela menção dos oráculos que o paralelo com outros heróis de calibre comparável se abre após a apresentação deste primeiro exemplar. E os ditames da transcendente sabedoria são consignados em escala progressiva, onde a excelência do Paflagónio apenas é excedida por um concorrente, dentro de um processo dinástico onde a hereditariedade se exprime numa espécie de sobrenome comum a todos os sujeitos reinantes: $\sigma \tau U \pi \tau \in\llcorner O \pi \omega ́ \lambda \eta \varsigma$ 'o negociante de estopas', como fun-

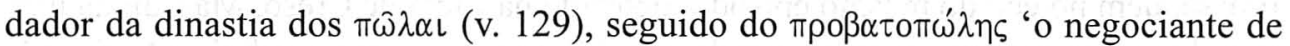

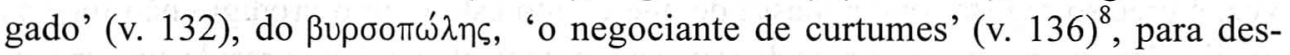
fechar no supra-sumo da classe, de vinda pomposamente cercada do mistério do transcendente como os grandes heróis da história, o $\alpha \lambda \lambda \alpha \nu \tau 0 \pi \omega$ ' $\lambda \eta \varsigma$, 'o negociante de chouriços' (v. 144) ${ }^{9}$. Na concentração que faz na profissão de $\pi \omega ́ \lambda \eta \varsigma$, que une todos os termos desta lista, o raciocínio é, em si, uma avaliação produzida de um ponto de vista colectivo, sem deixar de ser agonística, na escala progressiva de

Cf. v. 2, onde o nome é dado como a primeira informação concreta sobre o retratado, com todas as sugestões que potencialmente contém sobre a origem e o tom retórico do demagogo, logo repetido a espaços expressivos: nos vv. 6 e 44, aplicado ao modelo de uma raça

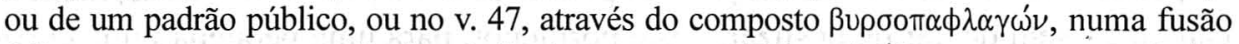
feliz com o elemento profissional; finalmente, no v. $919, \pi \alpha \phi \lambda \alpha \zeta_{\zeta L}$ serve para exprimir a ideia da 'borbulhagem' que a fervura provoca, aplicada no caso ao empolamento do Paflagónio, excitado pela ameaça da competição e exuberante nas reacções que manifesta.

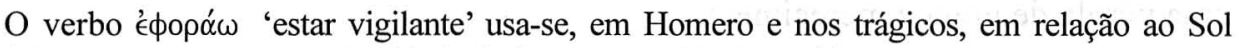
(Ilíada 3. 277, Odisseia 11. 109; Sófocles, Electra 824; Eurípides, Hipólito 849) e aos deuses (Odisseia 13. 214; Sófocles, Electra 175). Êupolis (fr. 316 K.-A.) aplica-o igualmente a Cléon, para definir a vigilância atenta que o demagogo exerce sobre a cidade de Atenas.

8 Antes de Cléon, o bem conhecido negociante de curtumes, dois outros são referidos como negociantes de estopas e de gado. De acordo com o escoliasta, trata-se respectivamente de Êucrates e de Lísicles (cf. ainda vv. 254, 765), figuras de relevância política discreta.

MacDowell, Aristophanes and Athens (Oxford 1995) 90, esclarece que estes leaders não detinham verdadeiramente um cargo; esta qualidade advinha-lhes simplesmente do prestígio que a opinião pública lhes garantia. Portanto o 'poder dinástico' em causa é o da popularidade e da capacidade efectiva de intervenção que ela traz. 
méritos que enuncia. Logo, o topo da escala está aberto à grandeza e à supremacia do recém-chegado Salsicheiro, trazido pela mão dos deuses. $O$ vocabulário que o caracteriza lembra um pouco o que é utilizado num texto famoso de Heródoto, onde Sólon, o sábio grego, e Creso, o todo poderoso senhor da Lídia, definem o modelo do que se pode considerar o mais próspero dos humanos (1. 29$32)^{10}$. O confronto entre o que se designa por $\epsilon \cup ̉ \delta \alpha \iota \mu o \nu i ́ \alpha$, 'felicidade', e por $\epsilon \cup ่ \tau U$ $\chi i \alpha$ 'sorte', detém, nesse caso, o cerne da reflexão. Entusiasmado com a promessa de salvação que o 'novo senhor' representa, o Primeiro Escravo de Cavaleiros

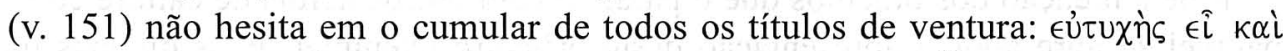
$\mu \in \gamma \alpha \dot{\alpha} \lambda \omega \varsigma \in \mathcal{\epsilon} \delta \alpha \iota \mu o \nu \in \hat{\iota} \zeta$, "és um felizão! Que sortalhaça a tua!" ${ }^{11}$. E logo, num empolamento persuasivo estimulado pelo cepticismo do sujeito das salsichas: 'Homem de sorte! Seu ricaço! Se hoje não és ninguém, amanhã vais estar nos píncaros! Ó soberano da feliz Atenas!' (vv. 157-159), onde $\mu \alpha \kappa \alpha ́ \rho\llcorner o \varsigma, ~ \pi \lambda o v ́ \sigma l o \varsigma ~ u ́ \pi t \epsilon \rho \mu \epsilon \gamma \alpha \varsigma$ prosseguem no eco do mesmo episódio ocorrido na Lídia de Creso. Mas, ainda uma vez, é preciso registar que a massa de que é feito este último prodígio não foge às qualidades comparáveis com as dos rivais; o potencial que detém reside em ser 'um

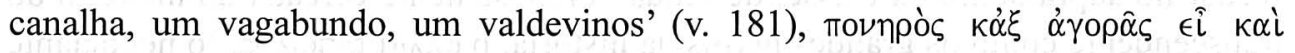

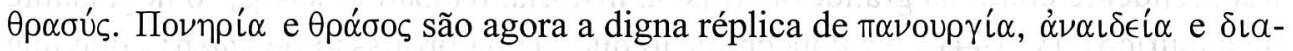
$\beta 0 \lambda \eta$, que caracterizaram antes o Paflagónio; 'vocação' política é também atributo de que não estão desprevenidos; por isso os dois rivais são parceiros perfeitos e equilibrados dentro de uma definição de paradigmas.

Um elemento da melhor convenção biográfica é, desta vez, aludido; às qualidades naturais acrescenta-se a instrução, a que tranquilamente o Salsicheiro responde (vv. 189-190): 'Conheço só as primeiras letras; e, mesmo essas, mal e porcamente', sem deixar de deslizar, neste pormenor, para uma pequena falha curricular; conhecer as primeiras letras, mesmo que apenas mal e porcamente, é um acréscimo de risco na ficha impoluta do verdadeiro político, onde a pura $\dot{\alpha} \mu \alpha \theta \dot{i} \alpha$ é uma pérola de grande merecimento.

Cumpre-se assim o proémio / prólogo com todas as componentes da convenção. Estão esboçados os modelos em apreço, com todos os traços necessários à elaboração do perfil de um chefe político: os que lhe advêm da massa do sangue, por vezes confirmados por razões de linhagem ou de tradição familiar; todos sujeitos ao

Para uma informação mais pormenorizada sobre este episódio, vide $\mathrm{T}$. Long, Repetition and variation in the short stories of Herodotus (Frankfurt 1987); H.-P. Stahl, 'Learning through suffering? Croesus's conversations in the History of Herodotus', YClS 24 (1975) 1-36.

11

Cf. vv. 172, 175. 
polimento da instrução ou da prática amadurecem o indivíduo para o exercício de uma função, onde todo o seu cabedal de prendas irá ser posto à prova.

O que é a actuação concreta do retratado ao longo das diversas étapas da existência concretiza-se, em Cavaleiros, em sucessivos agônes, sintomáticos de um curriculum profissional ascendente. Mostrar mérito, no plano agonístico da comédia, é enfrentar um opositor em combates progressivamente mais complexos: primeiro na casa do Povo, a cidade de Atenas na sua generalidade, para depois prosseguir no contexto, politicamente cada vez mais delicado, do Conselho e da Assembleia na Pnix. É aí que, em graduação, os méritos em causa são testados e medidos os graus supremos da arete democrática, em fases que distendem, com pormenores de comportamento, o núcleo sintético da caracterização antes simplesmente enunciado.

Um primeiro recontro assenta no poder da calúnia e da denúncia, a $\delta\llcorner\alpha \beta o \lambda \eta ́$ fulcral no exercício da política. Em ataques e contra-ataques inesgotáveis, os dois contendores brindam-se com todos os mimos da corrupção, roubo e falsidade. Logo uma segunda qualidade é posta à prova, a gritaria, ќ́кр $\alpha \gamma \mu \alpha$ e ßoń (vv. 285-287), recurso imprescindível ao bom sucesso. Depois o roubo, autêntico e confesso, comprovado pelo testemunho dos que foram vítimas de burlas memoráveis; como o ridículo de que se cobriu o Primeiro Escravo, cliente do Paflagónio dos curtumes, depois de comprar um bom par de sapatos que nem a caminhada até casa aguentou em condições (vv. 315-321). O combate prossegue, renhido, mas o coro adianta uma primeira vantagem para o Salsicheiro; às qualidades inatas que mal os distinguem, porque ambos demonstram possui-las em elevado grau, acrescenta este concorrente o benefício da pedagogia do mercado (vv. 328-334): 'Mas apareceu um outro tipo mais canalha do que tu e de longe (...), que te há-de derrubar e passar a perna (...) em safadeza, descaramento e trafulhice. Vamos, tu que te criaste na escola de onde saem os grandes homens de hoje em dia, é altura de mostrares que de nada vale uma boa educação'. É na paideia, mais do que na physis, que o Salsicheiro marca pontos. Foi na escola da vida que aprendeu (v. 293), não as primeiras letras, mas o que constitui de facto a bíblia do verdadeiro político. Trocou a escola pela ágora, ou seja, a teoria pela prática, e com tal opção lucrou em tempo e em competência. Dos méritos pedagógicos que lhe arredondaram as arestas da personalidade, o último dos negociantes pode valorizar (vv. 411-414): 'Foram tantos ou tão poucos os socos que apanhei desde criança, tantas as facadas, que estou certo de te vencer neste ponto; ou teria sido debalde que, criado a bolinhas de pão, me tornei no latagão que aqui vês'. Mais uma anedota traz o testemunho concreto à virtude descrita. A arte com que o menino prodígio da escola da vida exercitava os dotes que lhe não faltavam, ressalta da maneira, hábil na sua ingenuidade, como dis- 
traía os cozinheiros para thes filar um naco de carne (vv. 418-420). Tão simples quanto 'olha o passarinho!', e zás, carne para o bolso. E então se os lesados reclamavam, o prodígio revelava-se com maior subtileza ainda (vv. 423-424): escondia o furto no rabo e negava a pés juntos. Como não reconhecer neste golpe hábil de ocasião uma aptidão mais profunda e promissora? O rapaz estava talhado para a vida pública: se jurava falso, depois de roubar, e ... tinha a coisa metida no rabo! (vv. 426-428). Mão leve, língua pronta e traseiro às escâncaras, que atributos a natureza acumulou no seu eleito! Um pouco de prática e o prodígio transformou-se num verdadeiro génio.

Depois do primeiro recontro, outro terreno de maior exigência se abre à categoria dos lutadores. É diante do Conselho, perante um auditório expectante e treinado, que o embate seguinte vai ter lugar. Se o Paflagónio conta com a prerrogativa da experiência, para o Salsicheiro é chegado o momento de uma prova séria à sua capacidade (vv. 482-484): 'O caco e o bom senso que tens é agora altura de o pores à prova, se é verdadeira essa história que contaste da carne que escondeste no rabo'. Cada vez mais seguro e ousado nos atributos que constituem a sua ficha profissional, confiante no apoio dos aliados como no superior patrocínio dos deuses, do Conselho o Salsicheiro só pode trazer o relato de um enorme sucesso. A competência exigida não foi além das virtudes habituais. Apenas, neste outro plano, acrescia um auditório a persuadir e um concorrente a derrubar, o que exigia um potencial de qualidades não só em medida teórica, mas sobretudo na aplicação prática, para produzir um verdadeiro triunfo. Gritar e mentir perante o conselho, em si, não bastam. São potenciais que é preciso afinar à medida do momento. Gritar sim, mas o quê? Gritar denúncias contra os rivais, em arengas longas e tonitruantes, em estilo gongórico e atordoador; essa a escola que o Paflagónio praticava com sucesso (vv. 625-629), a julgar pela palidez raivosa dos conselheiros. Como respondeu o novato à vantagem do veterano? Abafando-lhe os gritos com gritaria superior, de boca escancarada até ao limite da ressonância (vv. 640-642). E além do tom, o teor do discurso abafou também a vantagem criada; às denúncias somou-se a sedução das promessas; e que outra notícia melhor do que uma baixa de preços nas sardinhas para opor ao adversário? Como verdadeiro profissional, o Salsicheiro atentou no alvo da sua retórica e captou-lhe os sinais favoráveis: de imediato os rostos serenaram. A ordem do processo subvertia-se; tratava-se apenas de rentabilizar a vantagem ganha com novas e crescentes promessas e mesmo com a gratuitidade de um brinde: uns pezinhos de coentro para condimentar o cozinhado. Com a bravura das coisas simples, a vitória não se fazia rogada. Voz e língua eram chamadas a agir agora, não só com o vigor ou com a capacidade de um potencial a explorar, mas com a flexibilidade que só a prática acrescenta à teoria, em ordem a uma verdadeira supremacia. 
Como última prova no cursus honorum ateniense, aos nossos heróis restava ainda o confronto final diante da autoridade do povo; de novo, um outro grau de dificuldade dependia da natureza de um outro auditório. Sobrava-lhe imprevisibilidade: instável nas preferências e decisões, susceptível à sedução e à promessa, guloso de confortos e de presentes, pouco leal nas preferências, assim se revelava essa entidade vaga que é o Povo. E então se reunido em assembleia, sentado na Pnix de voto na mão, até aos mais experientes causava tremores de susto (vv. 752-755). É neste terreno das ousadias limite que os políticos travam a prova final, na tentativa de garantirem para si os privilégios em que o povo não é parco, para quem lhe souber cativar as preferências. É este o campo das lutas de morte entre rivais, onde a popularidade se constrói e se derruba com a fragilidade de um jogo. O paleio e a mentira são aí mais úteis do que nunca, màs deles se exige uma subtileza máxima de cambiantes; protestos de amor, se necessário, com a modulação suave do afecto (v. 732): 'Povinho querido, estou louco por ti'; recordação de serviços prestados (v. 741): 'É preciso ver os favores que eu faço ao Povo'; promessas avançadas com generosidade. Mas sobre todo este potencial de recursos há que derramar o máximo de imaginação e ousadia. Não basta declarar afecto, há que acariciar; não chega prometer presentes, há que concretizá-los (vv. 784 sqq.); as mentiras têm de ter a força sobrenatural de oráculos; a conquista do povo investe em petiscos e guloseimas. A acompanhar o crescendo do retrato, a própria cena anima-se de símbolos concretos e visuais: multiplicam-se as prendas, uma almofada, uns sapatos, uma camisa. As mentiras são ditadas por oráculos, que saem de uma arca sem fundo e são depositados, em corrida servil, nas mãos do Povo. A adulação exprime-se, enfim, por aquela que é a grande metáfora da peça, a gastronomia. O roubo, esse, traduz-se agora por um cesto, onde o político guarda para si mais comida do que aquela com que empanturra o objecto dos seus amores, o querido povinho.

Cumprida a curva da vida dramática dos dois retratados, é chegada a hora do desfecho, que, na biografia, se exprime numa synkrisis, na comparação dos dois biografados em paralelo. É com processo semelhante que Aristófanes remata também o seu agôn. Finda a disputa, honras são prestadas ao vencedor, na acme do seu poder e fama. A coroa passa então, simbolicamente, da cabeça do Paflagónio para a do Salsicheiro (vv. 1227-1228). Uma recapitulação das características dominantes permite também a hierarquização dos contendores. Antes de entregar os pontos numa disputa que o empurra para a derrota, o Paflagónio certifica-se da superior idoneidade do adversário (vv. 1235-1236): 'Nos tempos de criança, em que escola andaste tu afinal?' 'Foi nos matadouros que me criei à força de soco'. Regressamos a um tópico de base, a instrução, que se confirma como a mais adequada ao biografado. Logo a 
profissão (vv. 1241-1242): 'E já homem feito, qual era a tua profissão?' 'Vendia chouriços e fazia uns servicinhos de mariquice'. E, por fim, teste derradeiro à condição social do novo senhor (vv. 1245-1246): 'E onde é que tu vendias os chouriços, na ágora ou às portas da cidade?' A sordidez dos subúrbios, terreno onde prosperara o Salsicheiro, catapulta-o enfim com segurança para a ribalta política. Com todos estes predicados, que concretizam a vantagem que detém sobre o rival, qualquer dúvida está desfeita, é ele o salvador prometido pelos oráculos.

Aprontam-se as cerimónias finais, que seguem caminhos inversos: coberto das galas da festa e circundado pela solenidade das grandes vitórias, o Salsicheiro alinha no cortejo festivo que cerca um Povo remoçado. Vencido, o Paflagónio recebe, para seu opróbrio, a banca dos chouriços e parte para os subúrbios, rendido a uma inevitável decadência. Coroas de glória para o vencedor, chouriços de morte política para o vencido, eis os símbolos expressivos da sucessão dos dois leaders.

Sem que o teatro clássico tivesse alguma vez definido técnicas de retrato ou modelos de biografia, a construção de uma comédia como Cavaleiros observa um conjunto de traços que não são estranhos ao esquema que posteriormente se convencionou para um novo género, a biografia. Não é, por isso, surpreendente que, tanta vez, nas grandes páginas que registaram vidas, a comédia se integre em citações explícitas, como sirva de fonte possível para a estrutura que lhes subjaz. Afinal a arte do retrato tinha encontrado, muitas gerações atrás, uma identidade.

\section{BIBLIOGRAFIA}

Brock, R. W.

- 'The double plot in Aristophanes' Knights', GRBS 27 (1986) 15-27.

Cerezo Magán, M.

- 'Algunas observaciones en torno a la originalidad de la técnica biográfica plutarquea', in J. A. F. Delgado, F. P. Pardo, Estudos sobre Plutarco: aspectos formales. Actas del IV Simposio Español sobre Plutarco (Madrid 1996) 267-279.

Edmunds, L.

- 'The Aristophanic Cleon's 'disturbance' of Athens', AJPh 108 (1987) 233-263.

MacDowell, D. M.

- Aristophanes and Athens (Oxford 1995).

Momigliano, A.

- The development of Greek biography (Harvard University Press 1993). 
Pérez Jiménez, A. P.

- 'La asociación de ideas como criterio formal en las Vidas Paralelas', in J. A. F. Delgado, F. P. Pardo, Estudos sobre Plutarco: aspectos formales. Actas del IV Simposio Español sobre Plutarco (Madrid 1996) 257-265.

Podlecki, A. J.

- Plutarch. Life of Pericles (Bristol 1987).

Russell, D. A.

- 'On reading Plutarch's Lives', G\&R 13 (1966) 139-154.

Stadter, $\mathrm{Ph}$.

- 'Anecdotes and the thematic structure of Plutarchean biography', in J. A. F. Delgado, F. P. Pardo, Estudos sobre Plutarco: aspectos formales. Actas del IV Simposio Español sobre Plutarco (Madrid 1996) 291-303.

- 'Plutarch's Lives: the statesman as moral actor', in C. Schrader, V. Ramón, J. Vela, Plutarco y la história. Actas del V Simposio Español sobre Plutarco (Saragoça 1997) 65-81. 


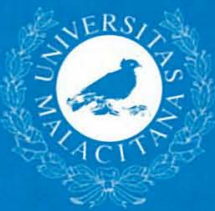

